\title{
A case of an ectopic cervical thymic cyst
}

\author{
Simon Davey*, Janet McNally \\ Department of Paediatric Surgery, Bristol Royal Hospital for Children, Bristol, UK; \\ *Corresponding Author: drsdavey@googlemail.com
}

Received 25 October 2012; revised 1 April 2013; accepted 16 April 2013

Copyright (C) 2013 Simon Davey, Janet McNally. This is an open access article distributed under the Creative Commons Attribution License, which permits unrestricted use, distribution, and reproduction in any medium, provided the original work is properly cited.

\begin{abstract}
Ectopic cervical thymic cysts are uncommon lesions and definitive preoperative diagnosis is not always possible. Surgical excision is recommended due to the small but possible chance of malignant degeneration in adulthood. We present a case of a nine-year-old boy with an asymptomatic lesion in his neck, discuss the differential diagnoses of such lesions and treatment considerations.
\end{abstract}

Keywords: Ectopic Thymic Cysts

\section{INTRODUCTION}

A nine-year-old boy presented with a two-month history of an asymptomatic left sided neck swelling which was identified on histological examination to be an ectopic thymic cyst. In this case report we consider the differential diagnoses of cystic lesions in the neck in children, the pathophysiology and treatment considerations.

\section{CASE REPORT}

A previously well nine-year-old boy presented with a two month history of an asymptomatic left sided neck swelling.

It was an ill-defined $4 \mathrm{~cm}$ by $3 \mathrm{~cm}$ soft, non-tender, cystic lesion in the left anterior triangle of the neck. Ultrasound demonstrated an avascular cystic structure, lateral to the left side of the thyroid, not typical for a cystic hygroma or branchial cyst. An MRI scan identified proteinaceous material within a bi-lobed cystic lesion (Figure 1), suggesting a branchial cyst but diagnostic uncertainty remained and an excision biopsy was performed.

Macroscopically, the specimen was multiloculated and contained "green, jelly-like material" with yellow areas in the wall. Microscopically the cyst wall contained thymic tissue with Hassall's corpuscles and cholesterol granulomas establishing the diagnosis of a thymic cyst.

\section{DISCUSSION}

Ectopic thymic cysts are rare lesions but should be considered in the differential diagnosis of cervical cystic lesions in children. Approximately $75 \%$ occur in patients under the age of 20 years of age [1] with the majority presenting between two and thirteen years [2]. Of these paediatric cases, $75 \%$ arise in boys in the first decade of life [1].

Ectopic thymic tissue can be cystic or solid. Cysts are more common, representing $71 \%$ of cases reported [1]. Although most are asymptomatic at presentation, 10\% were symptomatic. Symptoms described include: dyspnoea, stridor, dysphagia, upper respiratory tract infections and cervical pain [3].

The pathophysiology of ectopic thymic tissue is thought to be related to the pathway the developing thymus takes between the sixth and ninth week of embryonic life [2]. At six weeks, outgrowths from the 3rd pharyngeal pouch start to descend into the mediastinum. The developing thymic tissue travels through the piriform sinus, continues

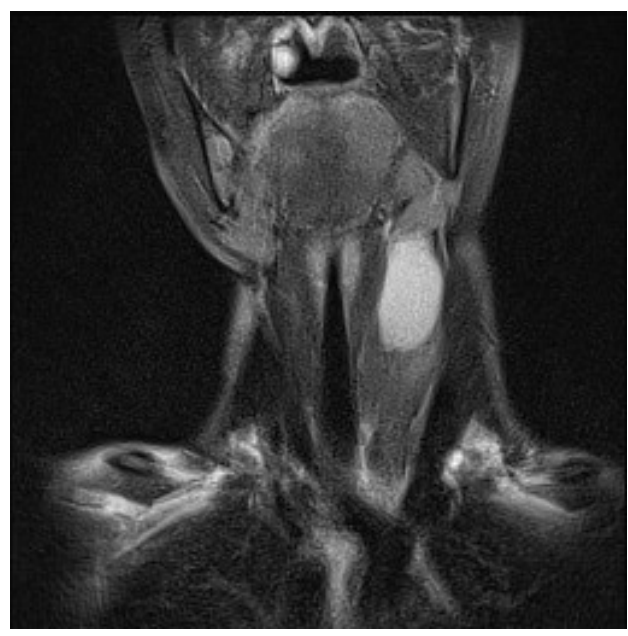

Figure 1. MRI scan demonstrating enhancing lesion in anterior triangle. 
Table 1. Summary of key characteristics of cystic lesions found in the neck.

\begin{tabular}{cccc}
\hline & Cystic hygroma & Branchial cyst & Thymic cysts \\
\hline Age & $90 \%<2$ years & 3rd decade & $75 \%<20$ years (mean age 12 years) \\
Composition & Multilocular & Unilocular & Unilocular \\
Location & Posterior triangle floor of mouth & Upper 1/3rd & Anterior triangle (left more common than right) \\
Mediastinal extension & Yes $(3 \%-10 \%)$ & No & Yes (50\%) \\
\hline
\end{tabular}

through the thyrohyoid membrane, between the carotid and vagus, behind the glossopharyngeal nerve and enters the anterior mediastinum lateral to the thyroid gland [4].

The differential diagnosis of cystic masses in the neck in children includes cystic hygromas, branchial cleft cysts, thryroglossal duct cysts, dermoid and teratoid cysts and cystic vascular abnormalities. Ectopic thymic cysts are frequently overlooked.

We briefly consider the features of the most common cystic lesions. Cystic hygromas tend to present before two years of age [2,5] and can enlarge rapidly due to a viral or bacterial infection. Branchial cleft cysts typically present in the upper third of the neck and present more commonly in the third decade of life [2], whereas, branchial sinuses or fistulae commonly present in childhood. Thyroglossal cysts in contrast present in the midline, reflecting the path that the thyroid takes as it migrates caudally. Dermoid cysts are also often in the midline, along lines of fusion and contain sebaceous material [5]. Table 1 summarises the key characteristics of cystic lesions in the neck.

Malignant degeneration is rare but has been reported [6]. It is more common in solid thymic remnants and tends to occur in adulthood.

Imaging is not usually diagnostic. However, MRI or CT scanning can be useful to identify mediastinal extension which occurs in $50 \%$ of cases and will demonstrate surrounding structures in more detail than ultrasonography [7].

Aspiration cytology is not helpful as one needs cyst wall tissue to establish a diagnosis. Excision biopsy remains the only way to reach a definitive diagnosis. Hassall's corpuscles and cholesterol granulomata are pathognomonic.

The diagnostic uncertainty of cystic lesions in the neck can impact on treatment options. In the last decade injection schlerotherapy has become a popular choice for treatment of cystic hygromas. Much of the literature identifies that thymic cysts were frequently misdiagnosed preoperatively as either branchial cysts or cystic hygromas. Given the difficulty of definitive pre-operative diagnosis and the theoretical risk of malignancy developing in later years, the diagnosis of ectopic thymic cysts should be considered.

\section{CONCLUSION}

Ectopic cervical thymic cysts are uncommon lesions. A definitive pre-operative diagnosis is not always possible and with the risk of malignant degeneration in adulthood, surgical excision is recommended where diagnostic uncertainty remains.

\section{REFERENCES}

[1] Meyer, E., Mulwafu, W., Fagan, J., Brown, R. and Taylor, K. (2010) Ectopic thymic tissue presenting as a neck mass in children: A report of 3 cases. Ear, Nose \& Throat Journal, 89, 228-231.

[2] Nguyen, Q., deTar, M., Wells, W. and Crockett, D. (1996) Cervical thymic cyst: Case reports and review of the literature. Laryngoscope, 106, 247-252.

[3] Öztürk, H., Karnal, I., Deveci, S., Sürer, I. and Çetinkursun, S. (2001) Multilocular cervical thymic cyst: An unusual neck mass in children. International Journal of Pediatric Otorhinolaryngology, 61, 249-252. doi:10.1016/S0165-5876(01)00542-0

[4] Scott, K., Schroeder, A. and Greinwald, H. (2002) Ectopic cervical thymus. An uncommon diagnosis in the evaluation of pediatric neck masses. Archives of Otolaryngology_Head and Neck Surgery, 128, 714-717.

[5] Hutson, J.M., O’Brien, M., Woodward, A.A. and Spencer, W.B. (2008) Jones' clinical paediatric surgery. 6th Edition, Blackwell Publishing Limited, Oxford, 107,298.

[6] Berridge, D. and Webb, A. (1986) Cervical thymus cyst and thyroglossal cyst carcinoma. British Journal of Surgery, 73, 44. doi:10.1002/bjs.1800730118

[7] Graeber, G., Thompson, L., Cohen, D., Ronnigen, L., Jaffin, J. and Zajtchuk, R. (1984) Cystic lesion of the thymus. An occasionally malignant cervical and/or anterior mediastinal mass. Journal of Thoracic and Cardiovascular Surgery, 87, 295-300. 